\section{"Evolução ClíNICA E LabORATORIAL DE RECÉM-NASCIDOS DE MÃES HIV POSITIVAS"}

No Brasil foram notificados mais de 362.364 casos de Aids desde 1980 até junho de 2004, sendo 3,8\% (13.786) de crianças até 13 anos de idade, cuja principal categoria de exposição foi a perinatal em mais de $84 \%$ das notificações. 0 número de crianças expostas vem aumentando pois, desde o surgimento dessa doença em nosso meio, tem sido observado o crescimento do número de casos entre mulheres em idade fértil com infecção pelo HIV/Aids, fato que persiste até os dias atuais com a verificação de que a epidemia cresce nove vezes mais entre as mulheres. Esses dados estão disponíveis no endereço eletrônico do Programa Nacional de DST/Aids (www.aids.gov.br).

Os primeiros casos de Aids pediátrica devido à transmissão vertical foram diagnosticados nos Estados Unidos da América a partir de 1982'. A transmissão vertical também é denominada infecção perinatal pelo HIV e transmissão mãefilho do HIV, e esses termos serão utilizados como sinônimos ao longo desse comentário. As taxas de transmissão no mundo são variáveis; antes do advento da disponibilidade de medidas preventivas situava-se ao redor de II\% a 14\% na Europa Ocidental, 20\% a 25\% nos Estados Unidos da América e entre $30 \%$ até $45 \%$ nos países africanos. Os dados disponíveis no Brasil apontavam taxas entre 16\% e 40\%, dependendo da taxa de aleitamento nesta população.

Na história natural da infecção pelo HIV/Aids em crianças, um dado que até hoje não é conhecido com precisão é quando a criança se infecta. Há indícios de que pode se infectar ao longo do período intra-uterino (estima-se que em cerca de $25 \%$ a $30 \%$ ), mas que os momentos próximos ao parto sejam os de maior risco (65\% a $70 \%)$. E ainda o risco de aquisição pós-natal, através do aleitamento materno, o qual situa-se entre 7\% até 39\% dependendo da época em que ocorreu a infecção materna (o risco é mais elevado quando a infecção é recente, pois haverá elevada taxa de replicação viral em relação a infecção previamente estabelecida, em que a carga viral pode estar mais estável).

O conhecimento de que a infecção pode ocorrer nesses vários momentos possibilitou a elaboração de uma proposta de intervenção profilática delineada por grupo de pesquisadores americanos e europeus, conhecida como protocolo 076 (a denominação correta é PACTG 076, que é abreviatura utilizada para Pediatric AIDS Clinical Trials Group, ou seja, Grupo de Estudos Clínicos de Aids Pediátrica), com a hipótese de que o uso da Zidovudina (AZT) durante a gravidez, trabalho de parto e para o recém-nascido, e a suspensão do aleitamento materno reduziriam o risco da transmissão vertical do HIV. Em 1992/I993, iniciaram estu- do constituído por um grupo de pares mães-crianças que receberam tratamento (AZT) e comparado com grupo placebo. Os achados do estudo constataram a redução da taxa de transmissão em aproximadamente 70\% (transmissão no grupo-AZT de 8,3 vs grupo-placebo de $25,5 \%)^{2}$. Essa terapia profilática, aliada a outras medidas tais como o aconselhamento universal e recomendação do teste antiHIV para todas as gestantes, a indicação de terapia antiretroviral para a gestante que se revelar soropositiva para o HIV, a indicação da via de parto - cesárea eletiva - em situações específicas e a suspensão do aleitamento materno podem contribuir para uma redução ainda maior do risco de transmissão perinatal. Assim, as taxas de transmissão mãefilho da infecção pelo HIV situam-se atualmente ao redor de 2\% nos Estados Unidos da América, em países europeus e, no Brasil, que adotou essas estratégias em todo o território nacional a partir de 1996, reduziu-se para cerca de 4\%, porém com taxas variáveis nas diferentes regiões.

O Ministério da Saúde elaborou estudo através da Rede Sentinela para quantificar o número de gestantes soropositivas para o HIV. Estima-se que no Brasil ocorram cerca de 3.000.000 de partos por ano, e que a prevalência de gestantes soropositivas situa-se ao redor de $0,56 \%$, esperando-se, desse modo, 17.200 gestantes infectadas pelo HIV por ano.

O objetivo do Programa Nacional de DST/Aids é identificar 100\% das gestantes infectadas pelo HIV. A recomendação atualmente definida para o território nacional é a do oferecimento universal do teste HIV para todas as gestantes, o que possibilitará o aconselhamento e a indicação do uso da zidovudina (AZT) para a prevenção da transmissão vertical do HIV nos moldes do protocolo ACTG 076, assim como outras medidas profiláticas. Esse esquema está disponível para toda a rede de atenção à saúde por meio do Programa Nacional de DST/Aids do Ministério da Saúde, por meio do denominado Projeto NASCER ${ }^{3}$.

O artigo de Yoshimoto et al. "Evolução clínica e laboratorial de recém-nascidos de mães portadoras do HIV", publicado nesta edição, à pagina 100 , avalia o risco de transmissão vertical da infecção pelo HIV depois da implantação da profilaxia em nosso meio e verifica que a taxa de transmissão foi de 9,3\%, constituindo-se informação de extrema utilidade, pois traduz como as medidas recomendadas para a profilaxia são adotadas na prática clínica nos serviços de saúde, destacando a sua importância. A despeito de haver uma política pública estabelecida, com recursos disponíveis para a sua execução, verifica-se que ainda há muito para ser feito na identificação das gestantes soropositivas.

Finalmente, os dados de um estudo recém-publicado de Souza Júnior et al. ${ }^{4}$ demonstrando que apenas 52\% das gestantes brasileiras receberam a cobertura efetiva das ações de prevenção da transmissão vertical no pré-natal 
durante o ano de 2002, a qual oscilou de acordo com a região do Brasil, sendo mais alta no sul (71\%) e consideravelmente mais baixa no nordeste $(24 \%)$ e, ainda, que as mulheres com maior nível de escolaridade tinham maior acesso a insumos e ações (64\% das mulheres com instrução superior ao primeiro grau) que as mulheres menos escolarizadas (19\% das mulheres sem instrução) também corroboram a necessidade de aprimorar a atenção ao prénatal, ao qual devem ser inquestionavelmente acrescidas todas as medidas para a redução da transmissão vertical do HIV assim como da sífilis congênita.

Heloísa Helena Marques
Referências

I. Ammann AJ. Is there an acquired immune deficiency syndrome in infants and children? Pediatr 1983, 72: 430-2.

2. Connor EM, Sperling RS, Gelber R, Kiselev P, Scott G, O'Sullivan MJ, VanDyke R, Bey M, Shearer W, Jacobson RL, et al. Reduction of maternal-infant transmission of human immunodeficiency virus type I with zidovudine treatment. Pediatric AIDS Clinical Trials Group Protocol 076 Study Group. N Engl J Med 1994; 331 : | |73-80.

3. Brasil. Ministério da Saúde. Secretaria de Vigilância em Saúde. Programa Nacional de DST/Aids. Projeto Nascer- Maternidades.

htpp://aids.gov.br/final/tratameto portaria2 I 042 I nov02 projetonascer.doc 4. Souza Junior PR, Szwarcwald CL, Barbosa Junior A, Carvalho MF, Castilho EA. Infecção pelo HIV durante a gestação: Estudo-Sentinela Parturiente, Brasil, 2002. Rev Saude Publica. 2004, 38:764-72. Epub $2004 \mathrm{Dec} 10$

\section{VACINAÇÃO ANTIPNEUMOCÓCICA EM CRIANÇAS COM DIABETES MELLITUS TIPO 1}

A vacinação antipneumocócica não faz parte do calendário oficial orientado pelo Ministério da Saúde do Brasil. Desde a década de 80, ela já é indicada para pacientes em situações especiais, por exemplo, diabéticos, por ser considerada uma importante intervenção para redução da morbi-mortalidade desses indivíduos'.

A orientação, recentemente divulgada pela Sociedade Brasileira de Pediatria, de inclusão da vacinação antipneumocócica para crianças até dois anos de idade no calendário vacinal provoca algumas reflexões ${ }^{2}$.

Investimentos têm sido feitos nos últimos anos para a produção de vacinas mais eficazes. Conforme dados publicados em 2003, a identificação das cepas de pneumococo causadoras de doença nas crianças brasileiras demonstra a possibilidade de proteção com o uso dessas vacinas $s^{3,4}$ e sua recomendação ${ }^{5}$.

As infecções pneumocócicas constituem importante causa de morbi-mortalidade em crianças, pessoas idosas ou portadoras de alguma condição clínica de base. A resistência bacteriana à penicilina, encontrada em algumas regiões, é um problema adicional a ser considerado 6 .

Em países desenvolvidos como os EUA, estima-se a ocorrência de 15-30 casos/100.000 pessoas/ano de bacteremia pneumocócica na população em geral, e 160 casos/l 00.000 em crianças. Pneumonia é a principal causa isolada de morte infantil; pneumonia pneumocócica é a causa mais comum de pneumonia adquirida na comunidade, tanto nos países em desenvolvimento quanto nos desenvolvidos. O S. pneumoniae é responsável por $25 \%$ a $35 \%$ dos casos de pneumonia que requerem hospitalização dos cerca de 500.000 que ocorrem anualmente nos EUA?

As infecções pneumocócicas causam, em média, 40.000 mortes/ano nos EUA, sendo que aproximadamente $50 \%$ delas seriam potencialmente evitadas pelo uso da vacina. Este índice de letalidade é maior que o de qualquer outra doença bacteriana prevenível por vacinação ${ }^{7}$.

No Brasil, a meningite pneumocócica é a segunda mais freqüente na infância, podendo levar a alto índice de seqüelas, com mortalidade de até $27,5 \%$. A alta incidência dessas infecções na população infantil aliada à gravidade potencial das mesmas certamente justifica a prevenção ${ }^{8}$.

No entanto, a diversidade de sorotipos dos pneumococos dificulta a produção de uma vacina eficaz. A vacina 23 -valente, que contém cerca de $85 \%$ a $90 \%$ dos sorotipos causadores de doença invasiva nos EUA, não oferece proteção para crianças abaixo de dois anos, devido às características da resposta imune ${ }^{7}$. A vacina conjugada heptavalente (PCV7), desenvolvida a partir dos principais sorotipos responsáveis por infecções invasivas nas crianças abaixo de seis anos, mostrou-se quase 100\% eficaz contra a doença pneumocócica invasiva ou resistência microbiana nos EUA? . Proteção semelhante não foi relatada no hemisfério Sul devido aos diferentes sorotipos.

No Brasil, considerando os sorotipos prevalentes em crianças até cinco anos, pressupõe-se cobertura para doença invasiva em torno de 52\%, podendo chegar a 